\title{
A comparative assessment of attitudes and hesitancy for influenza vis-à-vis COVID-19 vaccination among healthcare students and professionals in Malta
}

\author{
Sarah Cuschieri ${ }^{1}$ (D) Victor Grech ${ }^{2}$ \\ Received: 28 December 2020 / Accepted: 27 April 2021 / Published online: 25 May 2021 \\ (C) The Author(s), under exclusive licence to Springer-Verlag GmbH Germany, part of Springer Nature 2021
}

\begin{abstract}
Introduction Vaccine hesitancy has been a public health threat for decades, even among healthcare professionals. The study explored vaccination attitudes and hesitancy with regard to seasonal influenza and the anticipated Covid-19 vaccines among healthcare professionals and students.

Methods Anonymous questionnaires were distributed through electronic mail to healthcare professionals working in Malta's Health Division, at University of Malta, and in community pharmacies, and to members of Malta College of Family Doctors. Results The response rate was $18.60 \%(n=1802)$. The percentages of those who took the influenza vaccine last year $(2019)$ and who will take it this year (2020) increased across professionals, highest for family doctors and lowest for trainees in family medicine. The proportion of those likelier to take the Covid-19 vaccine was directly related to likelihood of taking influenza vaccination. Both family doctor trainees and nurses showed the highest Covid-19 vaccine hesitancy. Concerns pertaining to COVID-19 vaccination were mostly related to insufficient knowledge, although pharmacists (community, academic and students) were concerned about the rapid approval of the vaccine.

Conclusion An increase in influenza vaccine uptake is expected in view of the current Covid-19 pandemic. Of concern is the hesitancy towards Covid-19 vaccine particular within healthcare professionals, a cohort expected to be insightful and potential role models for the community. The associated hesitancy for both COVID-19 and influenza vaccination infers an intrinsic degree of vaccine hesitancy, which brings forward the need for healthcare professionals to be engaged in education, vaccination policies and administration in order to ensure compliance.
\end{abstract}

Keywords Vaccines $\cdot$ Corona $\cdot$ Influenza $\cdot$ Human flu $\cdot$ Healthcare $\cdot$ Malta

\section{Introduction}

Seasonal influenza is one of the major causes of respiratory tract infections with substantial morbidity and mortality (Cox and Subbarao 1999). Healthcare professionals are considered to be a source of influenza transmission. For this reason, healthcare professionals are encouraged to take the seasonal

Sarah Cuschieri

sarah.cuschieri@um.edu.mt

Victor Grech

victor.e.grech@gov.mt

1 Lecturer Anatomy Department, Faculty of Medicine and Surgery, University of Malta, Msida MSD2090, Malta

2 Mater Dei Hospital, Msida, Malta influenza vaccine every winter to protect themselves and their patients (Lorenc et al. 2017). However, a significant proportion of healthcare professionals decline seasonal influenza vaccination, with many European countries reporting vaccination among healthcare professionals below $30 \%$ (To et al. 2016). The behavioural origins of this vaccination hesitancy in this cohort are complex, with different influencing determinants such as pre-existing cultures, beliefs, social networks, local policies, and accessibility among others (Corace et al. 2016; Lorenc et al. 2017). Conversely, healthcare professionals' drivers for vaccination acceptance were reported as the desire to self-protect and protect their families (Dini et al. 2018).

The end of the year 2019 saw the emergence of a novel coronavirus SARS-CoV-2 (known as Covid-19) that presented with an influenza-like infection and a high infectivity rate, leading to a global pandemic (Zhang et al. 2020). Covid-19 
led to high morbidity and mortality rates across the world within a few weeks, especially among vulnerable populations (Cuschieri et al. 2021b). As winter approaches the Northern Hemisphere, a dual epidemic of seasonal influenza and Covid-19 is expected to occur, contributing to higher morbidity and mortality rates tremendously stressing healthcare systems (Gostin and Salmon 2020). In light of this, a universal coverage of seasonal influenza vaccination is encouraged to reduce the concurrent occurrence of a seasonal influenza infection with Covid-19 infection and the prospective poorer prognosis (Gostin and Salmon 2020). The majority of healthcare professionals have front-line roles during this pandemic and therefore are at higher risk of acquiring viral infections. For this reason, the administration of seasonal influenza vaccine - and when available Covid-19 vaccine - is of greater importance during this pandemic.

This study sets out to evaluate, compare, and contrast the attitudes and hesitancy for vaccination for influenza in the pre-Covid and Covid era vis-à-vis the anticipated Covid-19 vaccine, among the different healthcare professionals in Malta. Taxpayers in Malta enjoy free (at point of care, tax funded) primary and tertiary healthcare access which is readily available across the Islands (AzzopardiMuscat et al. 2017). The seasonal influenza vaccine is freely available to everyone every winter at the various healthcare centers and hospitals, yet significant vaccination hesitancy prevails. It should be noted that both community and hospital-based healthcare professionals are envisaged as role models and influencers for the rest of the public. Academics employed by the only state university in Malta (University of Malta) lecture across the different health faculties and have an influencing role on their students. For this reason, understanding their attitudes towards vaccination is essential. The students enrolled in health-related faculties will be the next generation of healthcare professionals, and it is therefore equally important to also comprehend their attitudes towards vaccination. Having an understanding of the attitudes, hesitancy, and potential barriers towards seasonal influenza and Covid-19 vaccine uptake within this influential cohort will enable public health authorities to understand the local scenario and plan targeted action plans.

\section{Materials and methods}

The study's protocol followed the University of Malta's Research Ethics Review Procedures and abided by the University's Research Code of Practice. A short anonymous questionnaire was prepared by one of the authors with the aim of establishing attitudes and hesitancy for influenza vis-à-vis COVID-19 vaccination within the healthcare sector (Supplement 1). Participants were informed that by accepting to participate in the survey they were giving their informed consent to participate. The questionnaire was hosted via Google forms ${ }^{\circledR}$ and data was exported to bespoke Excel spreadsheets for analysis.

This online link was distributed to healthcare employees working within the governmental health sectors between September and October 2020. All governmental healthcare workers in the main hospital (Mater Dei Hospital), District Primary Care Health Centres, St. Vincent de Paul Long Term Care Facility, Mount Carmel Mental Health hospital, Karin Grech Rehabilitation Hospital and miscellaneous other smaller facilities, received this questionnaire link through their governmental email account. The questionnaire link was distributed to the members of the Malta College of Family Doctors, in order to invite all practicing family doctors both in governmental and private sectors in Malta. Pharmacists also play an important role within the healthcare system. Hence, the questionnaire was sent out via the private Facebook group "Maltese Pharmacists and Pharmacy Students" to which almost all pharmacists and students subscribe. Furthermore, the study was carried out in the University of Malta among the faculties of Health Sciences (Allied Health), Dentistry, and Medicine by sending out the questionnaire link to academics within these faculties as well as to the respective enrolled students through their university email account. Permissions and clearances were granted by all the managerial heads of the different departments and sectors.

In this study, comparative analyses were performed across the different healthcare sectors. Comparative assessment using the Chi-square test was performed between academics, students, clinical/hospital pharmacists, community pharmacists, family doctors, family doctor trainees, other specialist doctors, nurses and allied health professionals. Allied health professionals included physiotherapists, midwives, and occupational therapists among others. For the purpose of this study, only pharmacists that reported working within a clinical/community setting were considered for analysis. Further comparisons were performed for the academics and students according to their faculty. A $p$ value $\leq 0.05$ was taken to represent a statistically significant result.

\section{Results}

A total of 9689 healthcare professionals and students were invited to participate in this survey. A response of $18.60 \%$ was achieved, with a female predominance $(65.15 \% \mathrm{CI}$ 95\%: 62.92-67.32 $p=<0.01$ ). Table 1 summarises the response rate by healthcare role as well as providing the demographic characteristics of the study population. 
Table 1 Summarizes the response rate by healthcare role and demographic characteristics of the study population by gender and age groups

\begin{tabular}{|c|c|c|c|c|c|c|c|c|c|c|c|}
\hline \multirow[t]{3}{*}{ Healthcare roles } & \multicolumn{3}{|c|}{ Participation } & \multicolumn{8}{|c|}{ Study population } \\
\hline & \multirow[b]{2}{*}{ Invited } & \multirow[b]{2}{*}{ Responders } & \multirow[b]{2}{*}{ Response rate } & \multicolumn{2}{|l|}{ Gender } & \multicolumn{6}{|c|}{ Age groups } \\
\hline & & & & Male & Female & $18-24$ & $25-34$ & $35-44$ & $45-54$ & $55-64$ & $>65$ \\
\hline Academics & 956 & 152 & $15.90 \%$ & $42.11 \%$ & $57.89 \%$ & $0.66 \%$ & $15.13 \%$ & $25.66 \%$ & $25.00 \%$ & $23.03 \%$ & $10.53 \%$ \\
\hline Students & 2081 & 679 & $32.63 \%$ & $32.25 \%$ & $67.75 \%$ & $78.50 \%$ & $15.46 \%$ & $4.12 \%$ & $1.47 \%$ & $0.44 \%$ & $0.00 \%$ \\
\hline Pharmacists & 735 & 73 & $9.93 \%$ & $17.81 \%$ & $82.19 \%$ & $2.74 \%$ & $42.47 \%$ & $32.88 \%$ & $10.96 \%$ & $9.59 \%$ & $1.37 \%$ \\
\hline Family doctors & 288 & 96 & $33.33 \%$ & $59.38 \%$ & $40.63 \%$ & $0.00 \%$ & $14.58 \%$ & $19.79 \%$ & $23.96 \%$ & $37.50 \%$ & $4.17 \%$ \\
\hline Family doctor trainees & 62 & 27 & $43.55 \%$ & $11.11 \%$ & $88.89 \%$ & $14.81 \%$ & $59.26 \%$ & $18.52 \%$ & $7.41 \%$ & $0.00 \%$ & $0.00 \%$ \\
\hline Other speciality doctors & 1472 & 203 & $13.79 \%$ & $49.26 \%$ & $50.74 \%$ & $14.29 \%$ & $40.89 \%$ & $22.66 \%$ & $11.33 \%$ & $9.85 \%$ & $0.99 \%$ \\
\hline Nursing & 2390 & 319 & $13.35 \%$ & $27.90 \%$ & $72.10 \%$ & $6.90 \%$ & $23.51 \%$ & $19.44 \%$ & $27.90 \%$ & $21.00 \%$ & $1.25 \%$ \\
\hline Allied health professionals & 1705 & 253 & $14.84 \%$ & $32.81 \%$ & $67.19 \%$ & $6.32 \%$ & $40.71 \%$ & $16.60 \%$ & $23.32 \%$ & $13.04 \%$ & $0.00 \%$ \\
\hline Total & 9689 & 1802 & $18.60 \%$ & $34.85 \%$ & $65.15 \%$ & $33.68 \%$ & $24.97 \%$ & $14.71 \%$ & $13.98 \%$ & $11.15 \%$ & $1.50 \%$ \\
\hline
\end{tabular}

\section{Attitudes towards influenza vaccine}

Less than half $(48.14 \%$ CI95\%: 46.00-50.28) of the healthcare professionals reported that they had taken the influenza vaccine in 2019 , with a female predominance $(61.11 \%$ C195\%: 58.06-64.07 $p=0.02$ ). Out of all the healthcare professionals, the highest uptake of influenza vaccine preCOVID (in 2019) was among family doctors, in contrast to their trainees in family medicine who had the lowest influenza vaccine uptake. However, for the year 2020 (Covid-19 era) the intention to take the influenza vaccine increased to $69 \%$ (CI 95\%: 66.98-70.94), yet again with a female predominance (63.38\% CI95\%: 60.86-65.83 $p=0.01)$. This increase was observed across the majority of the healthcare sector, as shown in Table $2(p=<0.001)$. It is noteworthy that all clinical/hospital-based pharmacists reported willingness to take the influenza vaccine this year (in 2020). On sub- categorising the academics and students by faculty, a general increase in the intention to take influenza vaccine for this year (2020) was observed across both academics and students. A significant increase in the intent to take the influenza vaccine was evident between students, with medical and pharmacy students expressing the highest intention, as shown in Table 3 .

\section{Attitudes towards COVID-19 vaccine}

Clinical/hospital-based pharmacists and family doctors reported the highest probability of taking the Covid-19 vaccine when it becomes available, as opposed to trainees in family medicine and nurses $(p=<0.01)$, as shown in Table 4. It was observed that healthcare professionals who opted to take the influenza vaccine were more likely to take the Covid-19 vaccine and vice-versa. Interestingly, a significant difference in the likelihood of taking Covid-19 vaccine could be observed
Table 2 Comparisons between the influenza vaccine uptake in 2019 and intention to take the influenza vaccine in 2020 across the healthcare sector

\begin{tabular}{|c|c|c|c|c|c|c|}
\hline \multirow[t]{2}{*}{ Healthcare roles } & \multicolumn{2}{|c|}{$\begin{array}{l}\text { Took influenza } \\
\text { vaccine in } 2019\end{array}$} & \multirow[b]{2}{*}{ Chi sq.* } & \multicolumn{2}{|c|}{$\begin{array}{l}\text { Intended to take } \\
\text { influenza vaccine in } \\
2020\end{array}$} & \multirow[b]{2}{*}{ Chi sq. } \\
\hline & Yes & No & & Yes & No & \\
\hline Academics $(n=152)$ & $52 \%$ & $48 \%$ & $<0.001$ & $77 \%$ & $23 \%$ & $<0.001$ \\
\hline Students $(n=679)$ & $43 \%$ & $57 \%$ & & $68 \%$ & $32 \%$ & \\
\hline Clinical/hospital pharmacists $(n=13)$ & $62 \%$ & $38 \%$ & & $100 \%$ & $0 \%$ & \\
\hline Community pharmacists $(n=37)$ & $51 \%$ & $49 \%$ & & $78 \%$ & $22 \%$ & \\
\hline Family doctors $(n=96)$ & $72 \%$ & $28 \%$ & & $72 \%$ & $28 \%$ & \\
\hline Family doctor trainees $(n=27)$ & $37 \%$ & $63 \%$ & & $37 \%$ & $63 \%$ & \\
\hline Other speciality doctors $(n=203)$ & $67 \%$ & $33 \%$ & & $86 \%$ & $14 \%$ & \\
\hline Nurses $(n=319)$ & $44 \%$ & $56 \%$ & & $62 \%$ & $38 \%$ & \\
\hline Allied health professionals $(n=253)$ & $42 \%$ & $58 \%$ & & $67 \%$ & $33 \%$ & \\
\hline
\end{tabular}

*The Chi-square test compares the influenza vaccine uptake/intent between the different healthcare professional roles 
Table 3 Comparisons between academics and students across different healthcare faculties for influenza vaccine uptake in 2019 and intention to take the influenza vaccine in 2020

\begin{tabular}{|c|c|c|c|c|c|c|}
\hline & & \multicolumn{4}{|l|}{ Faculty } & \multirow[b]{2}{*}{ Chi sq. } \\
\hline & & Medicine & Dentistry & Allied health & Pharmacy & \\
\hline \multicolumn{7}{|c|}{ Took influenza vaccine in 2019} \\
\hline \multirow[t]{2}{*}{ Academics } & Yes & $52.11 \%$ & $53.13 \%$ & $52.27 \%$ & $40.00 \%$ & 0.961 \\
\hline & No & $46.48 \%$ & $46.88 \%$ & $47.73 \%$ & $60.00 \%$ & \\
\hline \multirow[t]{3}{*}{ Students } & Yes & $51.41 \%$ & $42.86 \%$ & $30.86 \%$ & $30.30 \%$ & $<0.001$ \\
\hline & No & $48.07 \%$ & $57.14 \%$ & $69.14 \%$ & $69.70 \%$ & \\
\hline & & Medicine & Dentistry & Allied health & Pharmacy & Chi Sq. \\
\hline \multicolumn{7}{|c|}{ Intended to take influenza vaccine in 2020} \\
\hline \multirow[t]{2}{*}{ Academics } & Yes & $74.65 \%$ & $75.00 \%$ & $79.55 \%$ & $100.00 \%$ & 0.820 \\
\hline & No & $23.94 \%$ & $25.00 \%$ & $18.18 \%$ & $0.00 \%$ & \\
\hline \multirow[t]{2}{*}{ Students } & Yes & $76.09 \%$ & $69.39 \%$ & $48.00 \%$ & $62.12 \%$ & $<0.001$ \\
\hline & No & $22.62 \%$ & $30.61 \%$ & $51.43 \%$ & $37.88 \%$ & \\
\hline
\end{tabular}

between students enrolled in different faculties. Medical students expressed a higher intent to take the vaccine, as shown in Table 5.

Table 6 shows the Covid-19 vaccine concerns across the different healthcare professionals. Concern appeared to be related to the absence of adequate information on the vaccine and the potential long-term side-effects. However, trainees in family medicine were more concerned about the potential short side-effects and the possibility that the vaccine will be ineffective. The latter concern was shared with their senior colleagues, the family doctors. It should be noted that, out of the pharmacists' cohort, only the community-based pharmacists reported a concern about the vaccine being approved through an accelerated process. The same concern was shared among the academics (80\%) and students (53.03\%) under the auspices of the Department of Pharmacy at the University of Malta, unlike those of the other faculties.

\section{Discussion}

The study set out to compare attitudes and hesitancy for influenza and COVID-19 vaccination among the different healthcare professionals in Malta. The first Covid-19 pandemic wave in Malta was well controlled, with low morbidity and mortality rates (Cuschieri 2020). The second Covid-19 wave initiated in mid-July 2020 and is still on-going at the time of writing (end of November 2020). A higher community spread, morbidity, and mortality were observed when compared to the first wave as well as to other small islands in Europe (Cuschieri et al. 2020a, 2021b). Indeed, a strain on the healthcare system and healthcare professions was noted (Cuschieri et al. 2020a). This study was conducted in the midst of this second wave, where an average of 100 Covid19 cases per day were being reported. The increased workload on the health professionals might have impacted on the

Table 4 The likelihood of taking COVID-19 vaccine by the healthcare sector

\begin{tabular}{|c|c|c|c|c|c|c|}
\hline \multirow[b]{2}{*}{ Healthcare roles } & \multicolumn{5}{|c|}{ Likelihood of taking COVID-19 vaccine } & \multirow[b]{2}{*}{ Chi sq.* } \\
\hline & Highly unlikely & Unlikely & Neutral & Likely & Very likely & \\
\hline Academics $(n=152)$ & $9.87 \%$ & $3.29 \%$ & $20.39 \%$ & $24.34 \%$ & $42.11 \%$ & $<0.001$ \\
\hline Students $(n=679)$ & $6.92 \%$ & $11.93 \%$ & $24.74 \%$ & $22.53 \%$ & $33.87 \%$ & \\
\hline Clinical/hospital pharmacists $(n=13)$ & $7.69 \%$ & $0.00 \%$ & $15.38 \%$ & $46.15 \%$ & $30.77 \%$ & \\
\hline Community pharmacists $(n=37)$ & $8.11 \%$ & $5.41 \%$ & $27.03 \%$ & $16.22 \%$ & $43.24 \%$ & \\
\hline Family doctors $(n=96)$ & $5.21 \%$ & $3.13 \%$ & $20.83 \%$ & $29.17 \%$ & $41.67 \%$ & \\
\hline Family doctor trainees $(n=27)$ & $25.93 \%$ & $18.52 \%$ & $25.93 \%$ & $11.11 \%$ & $18.52 \%$ & \\
\hline Other speciality doctors $(n=203)$ & $10.34 \%$ & $5.42 \%$ & $14.78 \%$ & $22.17 \%$ & $47.29 \%$ & \\
\hline Nurses $(n=319)$ & $19.44 \%$ & $9.72 \%$ & $28.53 \%$ & $17.55 \%$ & $24.76 \%$ & \\
\hline Allied health professionals $(n=253)$ & $16.21 \%$ & $9.09 \%$ & $22.53 \%$ & $24.90 \%$ & $27.27 \%$ & \\
\hline
\end{tabular}

* The Chi-square test compares the likelihood of taking Covid-19 vaccine between the different healthcare professional roles 
Table 5 Comparisons between academics and students across different healthcare faculties on the likelihood of taking COVID19 vaccine

\begin{tabular}{|c|c|c|c|c|c|c|}
\hline & & \multicolumn{4}{|c|}{ How likely to take COVD19 vaccine } & \multirow[b]{3}{*}{ Chi sq." } \\
\hline & & \multicolumn{4}{|l|}{ Faculty } & \\
\hline & & Medicine & Dentistry & Allied health & Pharmacy & \\
\hline \multirow[t]{5}{*}{ Academics } & Highly unlikely & $11.27 \%$ & $9.38 \%$ & $6.82 \%$ & $20.00 \%$ & \multirow[t]{5}{*}{0.546} \\
\hline & Unlikely & $2.82 \%$ & $9.38 \%$ & $0.00 \%$ & $0.00 \%$ & \\
\hline & Neutral & $15.49 \%$ & $21.88 \%$ & $27.27 \%$ & $20.00 \%$ & \\
\hline & Likely & $25.35 \%$ & $15.63 \%$ & $27.27 \%$ & $40.00 \%$ & \\
\hline & Very likely & $45.07 \%$ & $43.75 \%$ & $38.64 \%$ & $20.00 \%$ & \\
\hline \multirow[t]{5}{*}{ Students } & Highly unlikely & $4.11 \%$ & $8.16 \%$ & $11.43 \%$ & $10.61 \%$ & \multirow[t]{5}{*}{$<0.001$} \\
\hline & Unlikely & $9.25 \%$ & $24.49 \%$ & $16.00 \%$ & $7.58 \%$ & \\
\hline & Neutral & $21.08 \%$ & $24.49 \%$ & $29.71 \%$ & $33.33 \%$ & \\
\hline & Likely & $24.16 \%$ & $20.41 \%$ & $18.29 \%$ & $25.76 \%$ & \\
\hline & Very likely & $41.39 \%$ & $22.45 \%$ & $24.57 \%$ & $22.73 \%$ & \\
\hline
\end{tabular}

* The Chi-square test compares the likelihood of taking Covid-19 vaccine between the different faculties for academics and students respectively response rate of this study. Concurrent with the rolling out of this study, a public health media campaign focusing on the importance of taking the seasonal influenza vaccine was being disseminated, which might have affected participants' attitudes and intentions to take influenza vaccine in the current year (2020). Indeed, on comparing those that reported taking the seasonal influenza in 2019 (pre-Covid) to those intending to take this vaccine this year (2020), a general increase across all healthcare professionals could be observed. Most healthcare professionals in Malta had first-hand experience with Covid-19 patients or relatives, which might have influenced their decision in taking the seasonal influenza shot this year, possibly to safeguard their loved-one's health apart from their own health. This is a promising observation with regard to the battle against healthcare professionals' vaccine hesitancy. However, it needs to be noted that those that expressed their intention to take the influenza vaccine might not have done so when the influenza vaccine was available.

It should be noted that the family doctors reported the lowest seasonal influenza hesitancy out of all the various participating healthcare professionals. Family doctors tend to have a higher frequency of intensive contact with vulnerable patients. and it is not uncommon that these patients are not completely protected by vaccination (Opstelten et al. 2010). Therefore, family doctors may feel a sense of obligation to protect their patients while simultaneously self-protecting themselves from influenza, especially if they themselves have underlying co-morbidities. Considering that family doctors tend to have a strong community influence, their positive attitude towards vaccination can be interpreted as a reflection of their advocacy for influenza vaccination to their patients and community. Interestingly, the trainees in family medicine expressed the highest hesitancy towards seasonal influenza vaccination even during the Covid-19 era. In view of the fact that these doctors will be caring for significant proportions of the community and vulnerable populations, this observation is truly troublesome. Such attitudes have been reported previously, and attributed to the perception by these young doctors of feeling they are healthy and can withstand minor sickness such as the flu (Opstelten et al. 2010). However, vaccination for influenza among young trainees has been reported to be a preventive measure for swab-positive influenza and respiratory tract infections (Barbara et al. 2006). Furthermore, these young doctors are more likely to form part of a young family with children, making them more susceptible to viral contact and spread (Barbara et al. 2006).

Interestingly, both medical and pharmacy students had a higher uptake and intention to take the influenza vaccination when compared to dental and allied health students. Previous studies have identified medical students as having a lack of motivation to take the influenza vaccine, with a higher susceptibility for injunctive norms (Lehmann et al. 2015). In this study, medical students appeared to have a different attitude towards vaccination, which may be attributed to their medical education programme, and this has been reported to play a vital role in vaccination acceptance (Gallone et al. 2017). Most of the medical lecturing programme in Malta is delivered by specialised doctors, which may also have an impact on their attitudes, especially considering that specialised doctors in this study exhibited a good vaccination acceptance. Furthermore, a proportion of medical students have been actively involved as volunteers in the Covid-19 swabbing centres in Malta, an act of solidarity that apart from being 


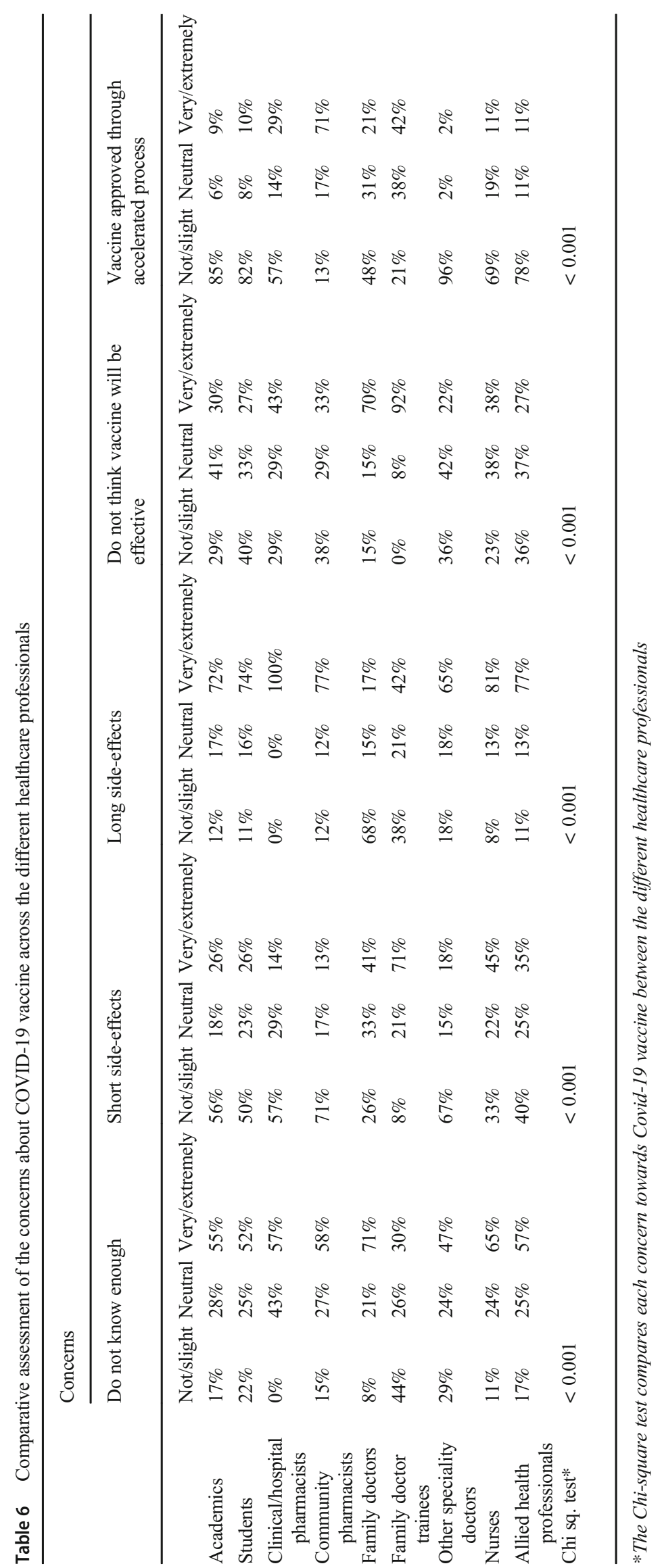


an educational experience, might have enabled a positive attitude towards vaccination (Cuschieri and Calleja Agius 2020).

\section{Attitude and hesitancy towards the anticipated Covid- 19 vaccination}

The anticipated Covid-19 vaccine is considered the long-term solution to the global pandemic (Danchin et al. 2020). Considering the reported lack of engagement of healthcare professionals with regard to vaccination even in this study, it was observed that those professionals opting for the influenza vaccine intended to take the Covid-19 vaccine, implying an innate degree of vaccine hesitancy/ resistance and not purely concerns on the innovativeness of this vaccine (Fisher et al. 2020). Indeed, the proportion intending to take the Covid-19 vaccine is similar to that reported in the US (Fisher et al. 2020). Family doctors exhibited the highest intention to take the Covid-19 vaccine along with the clinical/hospital-based pharmacists, as opposed to trainees in family medicine and nurses. In a similar study conducted in Israel, nurses reported being more vaccine hesitant than doctors, as noted in this study (Dror et al. 2020). The low vaccination acceptance by healthcare professionals will negatively impact on the containment of the viral spread and the build-up of herd immunity within the community. In fact, it has been reported that for Covid-19 community herd immunity to be established, $55 \%$ to $82 \%$ of the population needs to take the vaccine (Schaffer DeRoo et al. 2020). However, considering the economic crisis and Covid-19 restrictions implemented by governments, these situations might contribute to an increased compliance to vaccination by the general population and healthcare professionals. Nonetheless, hesitancy towards the Covid-19 vaccination was evident in this study, with the general hesitancy consensus being the concern about long side-effects and the absence of adequate information on the vaccine. The family medicine speciality (both specialists and trainees) reported a distinct concern about the effectiveness of the Covid-19 vaccine. On the other hand, the pharmacists cohort (community pharmacists, Department of Pharmacy academics and students) expressed the highest concern about the rapid approval of the vaccine, which coincides with their scientific background and experience in the pharmaceutical field. These various concerns are valid considering that a number of Covid-19 vaccines are in development, ranging from traditional vaccines to generational vaccines (Caddy 2020). However, there are other reasons not investigated in this study that may be contributing to vaccine hesitance including various vaccine myths such as "too many vaccines can overwhelm the immune system" (Geoghegan et al. 2020).

\section{Practical implications}

Healthcare professionals are a supposedly insightful population and play an important role in the community as role models. Hence, the presence of vaccination hesitancy among this cohort is very worrisome, particularly in the wake of the Covid-19 pandemic. Vaccine hesitancy is typically fuelled by conspiracy theories, fake news, and social media which may even have an affect among professionals (Grech 2017; Puri et al. 2020). Typically, vaccination hesitancy among healthcare professionals results from insufficient knowledge on the safety profile of vaccines (Millner et al. 2010), a finding which was noted in this study. Hence, this calls for vaccine transparency and availability of vaccine documentation to all healthcare professionals. On a population level, a national vaccination strategy should be set up prior to the vaccine availability to ensure population prioritisation and trust with regard to the vaccine, as well as to reduce misinformation and fake news. It is essential that all healthcare professionals are engaged, educated, and included in vaccination policies and administration to ensure compliance.

This study had a number of limitations that need to be pointed out. The questionnaire was not validated among the healthcare professionals, and the questionnaire did not record whether the responders had any underlying medical conditions. Hence, the study was not able to evaluate the relationship between the healthcare professional's vaccination attitudes and hesitance, and the presence of comorbidities. The online questionnaire was shared among the different healthcare professionals once through the institution electronic mail; should this mailshoot have be overseen or deleted, the professional was immediately categorised a non-responder.

\section{Conclusion}

Vaccine hesitancy is a public health problem and is also evident among healthcare professionals, even in the midst of a viral pandemic. Family doctors were observed to harbour the least resistance towards any vaccination when compared to the rest of the healthcare professionals. Although seasonal influenza vaccination appeared to appeal more to healthcare professionals during the Covid-19 era, it is still far from the ideal scenario. Indeed, this is reflected in the attitude towards the anticipated Covid-19 vaccine, with the commonest concern among healthcare professionals being insufficient knowledge on the vaccine safety profile.

Supplementary Information The online version contains supplementary material available at https://doi.org/10.1007/s10389-021-01585-z.

Acknowledgments We would like to thank the Deans of the Faculties of Allied Health (Prof. Roberta Sammut), Dentistry (Prof. Nikolai Attard) and Medicine (Prof. Godfrey LaFerla) along with the Administration staff for permitting and helping us to run this questionnaire.

Authors contributions VG gathered the data. SC analysed and wrote the manuscript draft. Both VG and SC reviewed and finalised the manuscript. 
Availability of data and materials Data is accessible upon request.

\section{Declarations}

Ethical approval The University of Malta Research Ethics Committee granted ethical approval for this study.

Consent of participants Participants gave their informed consent when accepting to participate in the survey.

Consent to publish Participants gave their consent to publish.

Competing interests Both authors declare no conflicts of interest.

\section{References}

Azzopardi-Muscat N, Buttigieg S, Calleja N, Merkur S (2017) Malta: Health system review. Health Syst Transit 19(1):1-137

Barbara M, Hilde P, Samuel C et al (2006) The effect of giving influenza vaccination to general practitioners: a controlled trial [NCT00221676]. BMC Med 4:17. https://doi.org/10.1186/17417015-4-17

Caddy S (2020) Developing a vaccine for Covid-19. BMJ 369:m1790. https://doi.org/10.1136/bmj.m1790

Corace KM, Srigley JA, Hargadon DP et al (2016) Using behavior change frameworks to improve healthcare worker influenza vaccination rates: a systematic review. Vaccine 34:3235-3242. https:// doi.org/10.1016/J.VACCINE.2016.04.071

Cox NJ, Subbarao K (1999) Influenza. Lancet 354:1277-1282. https:// doi.org/10.1016/S0140-6736(99)01241-6

Cuschieri S (2020) COVID-19 panic, solidarity and equity - the Malta exemplary experience. J Public Health (Berl.) 2020:1-6. https://doi. org/10.1007/s10389-020-01308-w

Cuschieri S, Calleja Agius J (2020) Spotlight on the shift to remote anatomical teaching during Covid-19 pandemic: perspectives and experiences from the University of Malta. Anat Sci Educ 13:671-679. https://doi.org/10.1002/ase.2020

Cuschieri S, Balzan M, Gauci C et al (2021a) Mass events trigger Malta's second peak after initial successful pandemic suppression. J Community Health 46:618-625. https://doi.org/10.1007/s10900020-00925-6

Cuschieri S, Pallari E, Hatziyianni A, Sigurvinsdottir R, Sigfusdottir I, Siguroardottir A (2021b) Mortality comparisons of Covid-19 with all-cause and non-communicable diseases in Cyprus, Iceland and Malta: lessons learnt and forward planning. Public Health. https:// doi.org/10.1016/j.puhe.2021.03.025

Cuschieri S, Pallari E, Hatziyiann A, et al (2020) Dealing with COVID19 in small European island states: Cyprus, Iceland and Malta. Early Hum Dev 2020:105261. https://doi.org/10.1016/j.earlhumdev. 2020.105261

Danchin M, Biezen R, Manski-Nankervis J-A et al (2020) Preparing the public for COVID-19 vaccines: how can general practitioners build vaccine confidence and optimise uptake for themselves and their patients? Aust J Gen Pract 49:625-629. https://doi.org/10.31128/ AJGP-08-20-5559

Dini G, Toletone A, Sticchi L et al (2018) Influenza vaccination in healthcare workers: a comprehensive critical appraisal of the literature. Hum Vaccin Immunother 14:772-789. https://doi.org/10. $1080 / 21645515.2017 .1348442$
Dror AA, Eisenbach N, Taiber S et al (2020) Vaccine hesitancy: the next challenge in the fight against COVID-19. Eur J Epidemiol 35:775779. https://doi.org/10.1007/s10654-020-00671-y

Fisher KA, Bloomstone SJ, Walder J, et al (2020) Attitudes toward a potential SARS-CoV-2 vaccine: a survey of U.S. adults. Ann Intern Med 173(12):964-973. https://doi.org/10.7326/M20-3569

Gallone MS, Gallone MF, Cappelli MG et al (2017) Medical students' attitude toward influenza vaccination: results of a survey in the University of Bari (Italy). Hum Vaccin Immunother 13:19371941. https://doi.org/10.1080/21645515.2017.1320462

Geoghegan S, O'Callaghan KP, Offit PA (2020) Vaccine safety: myths and misinformation. Front Microbiol 11:372. https://doi.org/10. 3389/fmicb.2020.00372

Gostin LO, Salmon DA (2020) The dual epidemics of COVID-19 and influenza. JAMA 324:335. https://doi.org/10.1001/jama.2020.10802

Grech V (2017) Fake news and post-truth pronouncements in general and in early human development. Early Hum Dev 115:118-120. https:// doi.org/10.1016/j.earlhumdev.2017.09.017

Grech V, Gauci C (2020) Vaccine hesitancy in the University of Malta Faculties of health sciences, dentistry and medicine vis-a-vis influenza and novel COVID-19 vaccination. Early Hum Dev 2020: 105258. https://doi.org/10.1016/j.earlhumdev.2020.105258

Grech V, Bonnici J, Zammit D (2020a) Vaccine hesitancy in Maltese family physicians and their trainees vis-a-vis influenza and novel COVID-19 vaccination. Early Hum Dev 2020:105259. https://doi. org/10.1016/j.earlhumdev.2020.105259

Grech V, Gauci C, Agius S (2020b) Vaccine hesitancy among Maltese healthcare workers toward influenza and novel COVID-19 vaccination. Early Hum Dev 2020:105213. https://doi.org/10.1016/j. earlhumdev.2020.105213

Lehmann BA, Ruiter RAC, Wicker S et al (2015) Medical students' attitude towards influenza vaccination. BMC Infect Dis 15:185. https://doi.org/10.1186/s12879-015-0929-5

Lorenc T, Marshall D, Wright K et al (2017) Seasonal influenza vaccination of healthcare workers: systematic review of qualitative evidence. BMC Health Serv Res 17:732. https://doi.org/10.1186/ s12913-017-2703-4

Millner VS, Eichold BH, Franks RD, Johnson GD (2010) Influenza vaccination acceptance and refusal rates among health care personnel. South Med J 103:993-998. https://doi.org/10.1097/SMJ. 0b013e3181eda3d5

Opstelten W, van Essen GA, Heijnen M-L et al (2010) High vaccination rates for seasonal and pandemic $(\mathrm{a} / \mathrm{H} 1 \mathrm{~N} 1)$ influenza among healthcare workers in Dutch general practice. Vaccine 28:61646168. https://doi.org/10.1016/j.vaccine.2010.07.031

Puri N, Coomes EA, Haghbayan H, Gunaratne K (2020) Social media and vaccine hesitancy: new updates for the era of COVID-19 and globalized infectious diseases. Hum Vaccin Immunother 16(11): 1780846. https://doi.org/10.1080/21645515.2020.1780846

Schaffer DeRoo S, Pudalov NJ, Fu LY (2020) Planning for a COVID-19 vaccination program. JAMA 323:2458. https://doi.org/10.1001/ jama.2020.8711

To KW, Lai A, Lee KCK et al (2016) Increasing the coverage of influenza vaccination in healthcare workers: review of challenges and solutions. J Hosp Infect 94:133-142. https://doi.org/10.1016/j.jhin. 2016.07.003

Zhang JJ, Dong X, Yuan CY et al (2020) Clinical characteristics of 140 patients infected with SARS-CoV-2 in Wuhan, China. Allergy Eur J Allergy Clin Immunol 75(7):1730-1741. https://doi.org/10.1111/ all.14238

Publisher's note Springer Nature remains neutral with regard to jurisdictional claims in published maps and institutional affiliations. 